ARMADA, Charles Alexandre Souza; LIMA, Raphael Leal Roldão. A cobrança pelo uso da água como importante instrumento jurídico-econômico da gestão hídrica no contexto da região nordeste. Revista Eletrônica Direito e Política, Programa de Pós-Graduação Stricto Sensu em Ciência Jurídica da UNIVALI, Itajaí, v.12, n.3, 30 quadrimestre de 2017. Disponível em: www.univali.br/direitoepolitica - ISSN 1980-7791

\title{
A COBRANÇA PELO USO DA ÁGUA COMO IMPORTANTE INSTRUMENTO JURÍDICO-ECONÔMICO DA GESTÃO HÍDRICA NO CONTEXTO DA REGIÃO NORDESTE
}

\author{
CHARGING OF WATER USE AS AN IMPORTANT LEGAL-ECONOMIC INSTRUMENT \\ OF WATER MANAGEMENT IN THE CONTEXT OF THE NORTHEAST REGION
}

\section{Charles Alexandre Souza Armada ${ }^{1}$}

\section{Raphael Leal Roldão Lima²}

SUMÁRIO: Introdução; 1 Recursos Hídricos no Planeta: Problemas Atuais e Perspectivas Futuras; 2 Recursos Hídricos no Brasil; 2.1 Breves considerações sobre a Política Nacional de Recursos Hídricos; 3 A Cobrança pelo Uso da Água e sua Importância como instrumento jurídico econômico no contexto próprio da Região Nordeste; 3.1 Sistemática Geral da Cobrança na PNRH; 3.2 Situação atual da cobrança pelo uso da água na Região Nordeste; Considerações finais; Referência das fontes citadas

\section{RESUMO}

Apesar de três quartos da superfície do planeta ser coberta de água, as parcelas para uso humano são ínfimas e mal distribuídas. Essa condição também se reflete em território brasileiro onde algumas regiões estão muito bem servidas de água doce enquanto outras vivenciam crises hídricas sucessivas. O presente trabalho tem como objetivo analisar a relação jurídico-econômica da cobrança pelo uso da água e, ao mesmo tempo, a necessidade do desenvolvimento sustentável e gestão responsável e equilibrada dos recursos hídricos. Depreendeu-se da pesquisa efetuada que o acesso a este recurso natural não se dá de forma homogênea em nosso país. Além disso, há problemas na distribuição e saneamento básico que interferem na qualidade de vida. A metodologia utilizada para desenvolvimento da pesquisa foi a indutiva e sua operacionalização se deu com base nas técnicas do referente, categorias básicas e conceitos operacionais.

PALAVRAS-ChAVE: Direito das Águas; Crise Hídrica; Recursos Hídricos

${ }^{1}$ Doutor em Ciência Jurídica do Curso de Pós-Graduação em Ciência Jurídica (CPCJ) do Centro de Ciências Sociais e Jurídicas (CEJURPS) da Universidade do Vale do Itajaí (UNIVALI). Doutor em Direito pela Universidade de Alicante, Espanha. Professor da Universidade do Vale do Itajaí (UNIVALI). Itajaí-SC. charlesarmada@hotmail.com

2 Especialista em Direito e Gestão Ambiental pela Universidade Federal da Bahia (UFBAUCSAL/BA). Especialista em Direito Processual Civil pela Universidade Salvador (UNIFACS/BA). Professor da Faculdade São Salvador. Salvador-BA. raphael@lealadv.com.br 
ARMADA, Charles Alexandre Souza; LIMA, Raphael Leal Roldão. A cobrança pelo uso da água como importante instrumento jurídico-econômico da gestão hídrica no contexto da região nordeste. Revista Eletrônica Direito e Política, Programa de Pós-Graduação Stricto Sensu em Ciência Jurídica da UNIVALI, Itajaí, v.12, n.3, 30 quadrimestre de 2017. Disponível em: www.univali.br/direitoepolitica - ISSN 1980-7791

\section{ABSTRACT}

Although three quarters of the planet's surface is covered by water, the plots for human use are tiny and poorly distributed. This condition is also reflected in Brazilian territory where some regions are very well served by fresh water while others experience successive water crises. The objective of this study is to analyze the legal-economic relationship between water use and the need for sustainable development and responsible and balanced management of water resources. The research concludes that the access to this natural resource does not take place homogeneously in our country. In addition, there are problems in distribution and basic sanitation that interfere with quality of life. The methodology used for the development of the research was the inductive and its operationalization was based on reference techniques, basic categories and operational concepts.

Key Words: Water Law; Water Crisis; Water Resources

\section{INTRODUÇÃO}

A cada dia se revela mais imperioso para a sociedade global, mormente ao Poder Público, que volte as suas atenções e ações para a preservação ambiental, associada a práticas de racionalização do uso e melhor distribuição dos recursos hídricos, vivenciando o meio ambiente de forma equilibrada e adotando novos instrumentos de educação, regulação, controle do consumo, fiscalização e proteção ambiental, dentre eles a implantação da cobrança pelo uso da água.

O presente trabalho se utiliza de fundamentos oriundos do Direito Ambiental, especificamente do 'Direito das Águas', objetivando analisar a relação jurídicoeconômica da cobrança pelo uso de um recurso natural com a necessidade do desenvolvimento sustentável e gestão responsável e equilibrada dos recursos hídricos.

Decerto que tal cobrança visa uma racionalização do próprio uso da água, e redução ou correção de distorções regionais de quantidade e qualidade hídrica, bem como a internalização pelos usuários dos efeitos ao meio ambiente, além da consequente efetivação do direito a um meio ambiente ecologicamente equilibrado.

Com isso, optou-se por dividir este trabalho em três seções, sendo estas: a) 
ARMADA, Charles Alexandre Souza; LIMA, Raphael Leal Roldão. A cobrança pelo uso da água como importante instrumento jurídico-econômico da gestão hídrica no contexto da região nordeste. Revista Eletrônica Direito e Política, Programa de Pós-Graduação Stricto Sensu em Ciência Jurídica da UNIVALI, Itajaí, v.12, n.3, 30 quadrimestre de 2017. Disponível em: www.univali.br/direitoepolitica - ISSN 1980-7791

Recursos hídricos no planeta: problemas atuais e perspectivas futuras; b) Recursos hídricos no Brasil; c) e Cobrança pelo uso da água e sua importância como instrumento jurídico econômico no contexto próprio da região Nordeste.

Nessa esteira, através de uma abordagem qualitativa, com pesquisas em diversas fontes documentais e bibliográficas pertinentes ao tema, tais como livros, teses, dissertações, artigos, textos normativos e matérias jornalísticas (documentação indireta), a primeira seção se propõe a realizar uma análise inicial dos dados estatísticos da situação crítica dos recursos hídricos do planeta, bem como da sua distribuição e consumo desigual entre os diversos países, tanto no aspecto quantitativo quanto qualitativo. Também é trazida ao debate a questão do crescimento da população mundial e o consequente aumento da demanda por tais recursos.

Na seção seguinte, serão abordados os aspectos hídricos do Brasil, ressaltando a sua condição de "potência global das águas", detentor de grandes reservas de água doce, porém - assim como no cenário internacional - com uma cruel disparidade de distribuição e acesso à água de qualidade no âmbito de seus Estados e Regiões. Além disso, serão trazidas breves considerações sobre a Política Nacional de Recursos Hídricos - PNRH, tais como os seus fundamentos, objetivos e instrumentos.

Na última seção, a discussão é encaminhada para o debate acerca da cobrança pelo uso da água e a sua importância como instrumento jurídico-econômico no contexto próprio da região Nordeste. Através da análise de aspectos importantes da cobrança, como a sua natureza jurídica, a sistemática da PNRH e a situação atual desse instituto no cenário da região Nordeste do Brasil.

A metodologia utilizada para desenvolvimento da pesquisa foi a indutiva e sua operacionalização se deu com base nas técnicas do referente, categorias básicas e conceitos operacionais. 
ARMADA, Charles Alexandre Souza; LIMA, Raphael Leal Roldão. A cobrança pelo uso da água como importante instrumento jurídico-econômico da gestão hídrica no contexto da região nordeste. Revista Eletrônica Direito e Política, Programa de Pós-Graduação Stricto Sensu em Ciência Jurídica da UNIVALI, Itajaí, v.12, n.3, 30 quadrimestre de 2017. Disponível em: www.univali.br/direitoepolitica - ISSN 1980-7791

\section{RECURSOS HÍdRICOS NO PLANETA: PROBLEMAS ATUAIS E PERSPECTIVAS FUTURAS}

Decerto que a água é um recurso natural essencial para a sobrevivência de todas as espécies que habitam o planeta. Com efeito, é importante recordar alguns dados que nos evidencia ainda mais seu protagonismo natural.

Nessa esteira, a água, doce ou salgada, está presente em boa parte do planeta Terra. A salgada é encontrada nos oceanos, que cobrem cerca de $75 \%$ (setenta e cinco por cento) da superfície do planeta e representa 97,5\% (noventa e sete vírgula cinco por cento) de toda a água. Com relação à água doce existente, apenas 2,5\% (dois vírgula cinco por cento) de toda a água do planeta é doce.

Do total de 2,5\% (dois vírgula cinco por cento) de água doce, 68,9\% (sessenta e oito vírgula nove por cento) correspondem às geleiras e calotas polares situadas em regiões montanhosas; $29,9 \%$ (vinte e nove vírgula nove por cento) são águas subterrâneas; $0,9 \%$ (zero vírgula nove por cento) compõem a umidade do solo e pântanos e apenas $0,3 \%$ (zero vírgula três por cento) constitui a água doce armazenada nos rios e lagos, efetivamente disponível para uso em diferentes atividades.

Dessa forma, é possível verificar que a água doce que existe no planeta é bastante escassa. Aliada a esta característica, sua distribuição não se dá de maneira uniforme. Atualmente, dois terços da população mundial vivem em áreas com escassez de água, ao menos durante um mês por ano e cerca de 500 milhões de pessoas moram em áreas nas quais o consumo de água excede em duas vezes os recursos hídricos renováveis localmente ${ }^{3}$.

Ainda tratando da desigual distribuição da água no planeta, Leonardo Boff argumenta que:

3 UNESCO. Relatório Mundial das Nações Unidas sobre Desenvolvimento dos Recursos Hídricos 2017, Resumo Dxecutivo. Disponível em: <http://unesdoc.unesco.org/images/0024/002475/247552por.pdf>. Acesso em: 17 jun. 2017. p. 2. 
ARMADA, Charles Alexandre Souza; LIMA, Raphael Leal Roldão. A cobrança pelo uso da água como importante instrumento jurídico-econômico da gestão hídrica no contexto da região nordeste. Revista Eletrônica Direito e Política, Programa de Pós-Graduação Stricto Sensu em Ciência Jurídica da UNIVALI, Itajaí, v.12, n.3, 30 quadrimestre de 2017. Disponível em: www.univali.br/direitoepolitica - ISSN 1980-7791

$60 \%$ da água doce do planeta se encontra em apenas nove países, enquanto que 80 outros enfrentam escassez. Pouco menos de um bilhão de pessoas consome $86 \%$ da água existente, enquanto ela é insuficiente para 1,4 bilhão (em 2020 serão três bilhões) $[\ldots]^{4}$.

Além disso, a qualidade da água que chega até as populações também tem se mostrado um problema para as parcelas mais pobres. Segundo o Relatório Mundial das Nações Unidas sobre Desenvolvimento dos Recursos Hídricos de 2017, 56\% (cinquenta e seis por cento) de toda água doce captada no planeta se torna água residual, ou seja, esgoto ou efluente industrial ou agrícola. Enquanto países de renda alta tratam cerca de $70 \%$ (setenta por cento) das águas residuais urbanas e industriais que produzem, essa proporção cai para $38 \%$ (trinta e oito por cento) nos países de renda média-alta, 28\% (vinte e oito por cento) nos países de renda média-baixa e para apenas $8 \%$ (oito por cento) nos países de renda baixa ${ }^{5}$.

De maneira a corroborar os baixos percentuais de tratamento de água, apresentados para os países de renda média-baixa e renda baixa, 2,4 bilhões ainda não têm acesso a tais instalações. Como resultado direto dos baixos percentuais de tratamento de água em níveis globais, estima-se que 842 mil mortes ocorridas em 2012 nos países de renda média e média-baixa foram causadas por água potável contaminada, por instalações inadequadas para a lavagem das mãos e por serviços sanitários inapropriados ou inadequados ${ }^{6}$.

Se a situação atual não é positiva, as perspectivas futuras também não podem ser classificadas de promissoras. De acordo com o Relatório Mundial das Nações

${ }^{4}$ BOFF, Leonardo. Sustentabilidade: o que é, o que não é. 4. ed. Petrópolis, RJ: Vozes, 2015. p. 117.

5 UNESCO. Relatório Mundial das Nações Unidas sobre Desenvolvimento dos Recursos Hídricos 2017, Resumo Disponível em: <http://unesdoc.unesco.org/images/0024/002475/247552por.pdf>. Acesso em: 17 jun. 2017. p. 2.

6 UNESCO. Relatório Mundial das Nações Unidas sobre Desenvolvimento dos Recursos Hídricos 2017, Resumo Executivo. Disponível em: <http://unesdoc.unesco.org/images/0024/002475/247552por.pdf>. Acesso em: 17 jun. 2017. p. 3. 
ARMADA, Charles Alexandre Souza; LIMA, Raphael Leal Roldão. A cobrança pelo uso da água como importante instrumento jurídico-econômico da gestão hídrica no contexto da região nordeste. Revista Eletrônica Direito e Política, Programa de Pós-Graduação Stricto Sensu em Ciência Jurídica da UNIVALI, Itajaí, v.12, n.3, 30 quadrimestre de 2017. Disponível em: www.univali.br/direitoepolitica - ISSN 1980-7791

Unidas sobre o Desenvolvimento de Recursos Hídricos 2015 - Água para um Mundo Sustentável, "em 2050, prevê-se um aumento da demanda hídrica mundial de 55\%, principalmente devido à crescente demanda do setor industrial, dos sistemas de geração de energia termoelétrica e dos usuários domésticos" 7 .

Além dos fatores já citados, é importante ressaltar alguns outros fatores diretamente relacionados com o aumento da demanda por água doce: o crescimento da população, a produção agrícola e demanda industrial manufatureira.

No que se refere ao crescimento da população mundial, estima-se um crescimento de 80 milhões de pessoas por ano, com estimativa de chegar a 9,1 bilhões em 2050, sendo 6,3 bilhões em áreas urbanas ${ }^{8}$.

O crescimento populacional assinalado também revela outro dado preocupante: cada vez mais se intensifica o crescimento das populações em áreas urbanas. Em 2007, pela primeira vez na história, a população urbana global excedeu a população rural global. Em 2014, 46\% da população mundial (3,4 bilhões de pessoas) vive nas áreas rurais. Prevê-se que a população urbana continue a crescer, de modo que, até 2050, o mundo será cerca de um terço rural (34\%) e dois terços urbano $(66 \%)^{9}$. Isso significa que os atuais 3,9 bilhões de pessoas que vivem em áreas urbanas alcançarão 6,3 bilhões em $2050^{10}$.

Ao tratar das demandas futuras do setor agrícola, a UNESCO aponta:

\footnotetext{
7 UNESCO. Relatório Mundial das Nações Unidas sobre Desenvolvimento dos Recursos Hídricos 2017, Resumo Executivo. Disponível em: <http://unesdoc.unesco.org/images/0024/002475/247552por.pdf>. Acesso em: 17 jun. 2017. p. 3 .
}

8 EBC. Mundo precisará mudar padrão de consumo para garantir abastecimento de água. Disponível em: <http://www.ebc.com.br/noticias/internacional/2015/03/mundo-precisaramudar-padrao-de-consumo-para-garantir-abastecimento>. Acesso em: 17 jun. 2017.

9 ONU - ORGANIZAÇÃO DAS NAÇÕES UNIDAS. World Urbanization Prospects: Revision 2014. Highlights. 2014. Disponível em: <http://goo.gl/ZaXUnE>. Acesso em: 18 jun. 2017. p. 7.

10 ONU - ORGANIZAÇÃO DAS NAÇÕES UNIDAS. World Urbanization Prospects: Revision 2014. Highlights. 2014. Disponível em: <http://goo.gl/ZaXUnE>. Acesso em: 18 jun. 2017. p. 11. 
ARMADA, Charles Alexandre Souza; LIMA, Raphael Leal Roldão. A cobrança pelo uso da água como importante instrumento jurídico-econômico da gestão hídrica no contexto da região nordeste. Revista Eletrônica Direito e Política, Programa de Pós-Graduação Stricto Sensu em Ciência Jurídica da UNIVALI, Itajaí, v.12, n.3, 30 quadrimestre de 2017. Disponível em: www.univali.br/direitoepolitica - ISSN 1980-7791

Até 2050 , a agricultura precisará produzir globalmente $60 \%$ a mais de alimentos, e $100 \%$ a mais nos países em desenvolvimento. Sendo já insustentáveis os atuais índices de crescimento global da demanda de água pela agricultura, o setor terá de aumentar sua eficiência no uso dessa água, reduzindo as perdas e, ainda mais importante, aumentando a produtividade das culturas em relação aos recursos hídricos utilizados ${ }^{11}$.

Já com relação à indústria manufatureira, entre 2000 e 2050, prevê-se um aumento de $400 \%$ (quatrocentos por cento) da demanda global de água, "afetando todos os outros setores, com a maior parte desse aumento ocorrendo em economias emergentes e em países em desenvolvimento" ${ }^{12}$.

Com base nos dados apresentados, tem-se patente que a demanda global por água tende a aumentar em várias frentes. As perspectivas relacionadas com a demanda de água doce no planeta sugerem, portanto, ações que considerem esse aumento de demanda, bem como os atuais índices de escassez, a distribuição não homogênea e o desperdício no tratamento adequado.

\section{RECURSOS HÍDRICOS NO BRASIL}

O Brasil é a potência global das águas, com 13\% (treze por cento) de toda água doce do planeta, perfazendo um total de 5,4 trilhões de metros cúbicos ${ }^{13}$.

Em termos comparativos com os demais países da América do Sul, o Brasil detêm 53\% (cinquenta e três por cento) da água doce do continente sulamericano. Nesse diapasão, cumpre recordar que o território brasileiro concentra dois dos maiores reservatórios de água subterrânea da Terra: o Sistema Aquífero

\footnotetext{
11 UNESCO. Relatório Mundial das Nações Unidas sobre o Desenvolvimento de Recursos Hídricos 2015 - Água para um Mundo Sustentável. Disponível em: <http://www.unesco.org/fileadmin/MULTIMEDIA/HQ/SC/images/WWDR2015ExecutiveSummary_P OR_web.pdf>. Acesso em: 17 jun. 2017. p. 3.
}

12 UNESCO. Relatório Mundial das Nações Unidas sobre o Desenvolvimento de Recursos Hídricos 2015 - Água para um Mundo Sustentável. Disponível em: <http://www.unesco.org/fileadmin/MULTIMEDIA/HQ/SC/images/WWDR2015ExecutiveSummary_P OR_web.pdf >. Acesso em: 17 jun. 2017. p. 3.

13 BOFF, Leonardo. Sustentabilidade: o que é, o que não é. p. 117. 
ARMADA, Charles Alexandre Souza; LIMA, Raphael Leal Roldão. A cobrança pelo uso da água como importante instrumento jurídico-econômico da gestão hídrica no contexto da região nordeste. Revista Eletrônica Direito e Política, Programa de Pós-Graduação Stricto Sensu em Ciência Jurídica da UNIVALI, Itajaí, v.12, n.3, 30 quadrimestre de 2017. Disponível em: www.univali.br/direitoepolitica - ISSN 1980-7791

Guarani e o Aquífero Alter do Chão (duas vezes maior do que o Aquífero Guarani) ${ }^{14}$.

Apesar de toda a riqueza hídrica apresentada, o Brasil compartilha alguns problemas globais relacionadas com esse recurso e convive, ao mesmo tempo, com alguns problemas específicos.

Embora o território brasileiro apresente grandes reservas de água doce, conforme exposto, destaca-se uma réplica da má distribuição apresentada no cenário internacional uma vez que "mais de 40 milhões de brasileiros não recebem água de forma regular, não podem confiar na qualidade da água que chega às suas torneiras e vivem sob um penoso regime de rodízio ou racionamento"15.

Enquanto a Região Hidrográfica Atlântico Nordeste Oriental - região com maior escassez de água e que abrange os estados do Rio Grande do Norte e Paraíba, parte do Ceará, Pernambuco e Alagoas e trechos do Piauí - apresenta disponibilidade hídrica inferior a $100 \mathrm{~m}^{3} / \mathrm{s}$, a Região Hidrográfica Amazônica - que abrange os estados do Amazonas, Amapá, Acre, Rondônia e Roraima, além de parcelas do Pará e Mato Grosso - apresenta disponibilidade hídrica bastante elevada, alcançando vazões de $74 \mathrm{mil} \mathrm{m}^{3} / \mathrm{s}^{16}$.

A recente crise hídrica vivenciada pela região Sudeste do Brasil, a partir de 2014, já havia sido antecipada pelo relatório Atlas Brasil de 2010, da Agência Nacional de Águas:

A capacidade total dos sistemas produtores instalados e em operação no país é de, aproximadamente, $587 \mathrm{~m}^{3} / \mathrm{s}$,

14 REBOUÇAS, Aldo. O paradoxo brasileiro. Cadernos Le Monde Diplomatique, São Paulo: Instituto Abaporu. n. 3, 2003. p. 38.

15 REBOUÇAS, Aldo. O paradoxo brasileiro. Cadernos Le Monde Diplomatique, São Paulo: Instituto Abaporu. n. 3, 2003. p. 38.

16 BRASIL. Agência Nacional de Águas - ANA. Atlas Brasil: abastecimento urbano de águas: panorama nacional. Brasília: ANA: Engecorps/Cobrape, 2010. Disponível em: <http://atlas.ana.gov.br/Atlas/downloads/atlas/Resumo\%20Executivo/Atlas\%20Brasil\%20\%20Volume\%201\%20-\%20Panorama\%20Nacional.pdf>. Acesso em: 24 jun. 2017. p. 29. 
ARMADA, Charles Alexandre Souza; LIMA, Raphael Leal Roldão. A cobrança pelo uso da água como importante instrumento jurídico-econômico da gestão hídrica no contexto da região nordeste. Revista Eletrônica Direito e Política, Programa de Pós-Graduação Stricto Sensu em Ciência Jurídica da UNIVALI, Itajaí, v.12, n.3, 30 quadrimestre de 2017. Disponível em: www.univali.br/direitoepolitica - ISSN 1980-7791

bastante próxima às demandas máximas atuais (em torno de $543 \mathrm{~m}^{3} / \mathrm{s}$ ), demonstrando que grande parte das unidades está no limite de sua capacidade operacional ${ }^{17}$.

No sentido de solucionar os problemas de abastecimento e pressão sobre os sistemas de produção de água existentes (isolados ou integrados), o relatório concluía a necessidade de investimentos em água e esgotos da ordem de $\mathrm{R} \$ 70$ bilhões ${ }^{18}$.

A escassez hídrica verificada em alguns Estados brasileiros, mormente os da Região Nordeste, configura um dado preocupante principalmente pelo fato que a demanda por água é crescente no Brasil. De acordo com o Atlas, as estimativas de demanda média para abastecimento da população urbana brasileira para o ano de 2025, na comparação com os dados de 2005, devem apresentar um crescimento de $28 \%$ (vinte e oito por cento) ${ }^{19}$.

O consumo médio per capita de água, considerando os volumes utilizados para satisfazer os consumos domésticos, comercial, público e industrial, demonstra que há certa disparidade entre as regiões brasileiras. De acordo com o Diagnóstico dos Serviços de Água e Esgotos - 2015, as médias regionais apuradas em 2015 para os três anos anteriores resultaram em "192,2 litros por habitante/dia na região Sudeste, 158,7 litros na região Centro-Oeste, 155,3 litros na região Norte, 150,9 litros na região Sul e 125,3 litros na região Nordeste" 20.

\footnotetext{
17 BRASIL. Agência Nacional de Águas - ANA. Atlas Brasil: abastecimento urbano de águas: panorama nacional. Brasília: ANA: Engecorps/Cobrape, 2010. Disponível em: <http://atlas.ana.gov.br/Atlas/downloads/atlas/Resumo\%20Executivo/Atlas\%20Brasil\%20\%20Volume\%201\%20-\%20Panorama\%20Nacional.pdf>. Acesso em: 24 jun. 2017. p. 67.

18 BRASIL. Agência Nacional de Águas - ANA. Atlas Brasil: abastecimento urbano de águas: panorama nacional. Brasília: ANA: Engecorps/Cobrape, 2010. Disponível em: <http://atlas.ana.gov.br/Atlas/downloads/atlas/Resumo\%20Executivo/Atlas\%20Brasil\%20\%20Volume\%201\%20-\%20Panorama\%20Nacional.pdf>. Acesso em: 24 jun. 2017. p. 67-68.
}

19 BRASIL. Agência Nacional de Águas - ANA. Atlas Brasil: abastecimento urbano de águas: panorama nacional. Brasília: ANA: Engecorps/Cobrape, 2010. Disponível em: <http://atlas.ana.gov.br/Atlas/downloads/atlas/Resumo\%20Executivo/Atlas\%20Brasil\%20\%20Volume\%201\%20-\%20Panorama\%20Nacional.pdf>. Acesso em: 24 jun. 2017. p. 24.

20 BRASIL. Ministério das Cidades. Secretaria Nacional de Saneamento Ambiental - SNSA. Sistema Nacional de Informações sobre Saneamento: Diagnóstico dos Serviços de Água e Esgotos - 2015. Brasília: SNSA/MCIDADES, 2017. p. 36. 
ARMADA, Charles Alexandre Souza; LIMA, Raphael Leal Roldão. A cobrança pelo uso da água como importante instrumento jurídico-econômico da gestão hídrica no contexto da região nordeste. Revista Eletrônica Direito e Política, Programa de Pós-Graduação Stricto Sensu em Ciência Jurídica da UNIVALI, Itajaí, v.12, n.3, 30 quadrimestre de 2017. Disponível em: www.univali.br/direitoepolitica - ISSN 1980-7791

As disparidades verificadas no consumo médio de água, principalmente na comparação entre a região Sudeste e a região Nordeste, também estão presentes quando se analisa o índice de atendimento com rede coletora de esgotos. Enquanto a média nacional apresenta um percentual igual a $58 \%$ (cinquenta e oito por cento) de atendimento, a região Sudeste representa $81,9 \%$ (oitenta e um vírgula nove por cento) e a região Norte 11,2\% (onze vírgula dois por cento) $)^{21}$.

Existe, em grande parte, um grande desperdício de água em sistemas de abastecimento, que perdem uma quantidade muito elevada de litros em razão de vazamentos e problemas gerais nas tubulações e sistemas de fornecimento. São as chamadas perdas reais decorrentes de vazamentos em adutoras, redes, ramais, conexões, reservatórios e outras unidades operacionais do sistema.

Algum nível de perda na distribuição da água também é verificado em países desenvolvidos. Na Austrália, por exemplo, 7\% (sete por cento) de toda a água é desperdiçada nos sistemas públicos, enquanto nos Estados Unidos esse número chega a $13 \%$ (treze por cento) 22 .

Já o desperdício de água no Brasil é bem mais elevado, atingindo um volume total correspondente a $36,7 \%$ (trinta e seis vírgula sete por cento) de toda a água tratada, segundo dados do Ministério das Cidades. Em algumas regiões, como o Norte e o Nordeste do país, esse índice aproxima-se dos 50\% (cinquenta por cento), revelando a carência de medidas para o combate ao desperdício.

O relatório do Ministério das Cidades mostra, ainda, as disparidades do índice de perda de água entre os Estados da Federação. Enquanto os Estados da Região Sudeste apresentam uma perda média de 33,7\%, alguns Estados das regiões

21 BRASIL. Ministério das Cidades. Secretaria Nacional de Saneamento Ambiental - SNSA. Sistema Nacional de Informações sobre Saneamento: Diagnóstico dos Serviços de Água e Esgotos - 2015. Brasília: SNSA/MCIDADES, 2017. p. 25.

22 TREVISAN, Karina. Brasil fica na $20^{a}$ posição em ranking internacional de perda de água. G1, São Paulo, 30 mar. 2015. Disponível em: <http://g1.globo.com/economia/crise-daagua/noticia/2015/03/brasil-fica-na-20-posicao-em-ranking-internacional-de-perda-deagua.html>. Acesso em: 25 jun. 2017. 
ARMADA, Charles Alexandre Souza; LIMA, Raphael Leal Roldão. A cobrança pelo uso da água como importante instrumento jurídico-econômico da gestão hídrica no contexto da região nordeste. Revista Eletrônica Direito e Política, Programa de Pós-Graduação Stricto Sensu em Ciência Jurídica da UNIVALI, Itajaí, v.12, n.3, 30 quadrimestre de 2017. Disponível em: www.univali.br/direitoepolitica - ISSN 1980-7791

Norte e Nordeste ultrapassam o índice de $60 \%$ de perda, caso do Maranhão, com $62,6 \%$, e Amapá, com $74,8 \%$ de perda 23 .

Em grande parte, o problema é causado tanto pela falta de manutenção de equipamentos públicos quanto pelo emprego de materiais mais baratos, além da elevada pressão, extravasamento de reservatórios, ligações hidráulicas clandestinas, entre outros.

Além dos problemas relacionados com o desperdício na distribuição de água, o país enfrenta também o problema do saneamento. A proporção de domicílios que dispunham de serviços de rede coletora de esgoto passou de 63,4\% em 2013 para 63,5\% em 2014. As Regiões Norte (21,2\%), Nordeste (41,1\%), CentroOeste $(46,5 \%)$ e Sul $(61,9 \%)$, apresentam percentuais de domicílios com acesso a este serviço inferior à média nacional; enquanto a Região Sudeste continuou sendo a região com a maior cobertura desse serviço, com $87,7 \%$ dos domicílios atendidos ${ }^{24}$.

Somados a todos esses fatores, é preciso ressaltar também a grave situação climática da seca ou estiagem prolongada, que atinge inúmeros estados brasileiros e principalmente aqueles integrantes da Região Nordeste.

Em entrevista concedida no ano de 2016, o Meteorologista David Ferran, pesquisador da Fundação Cearense de Meteorologia e Recursos Hídricos, afirmou que a gravidade e severidade da seca que atinge praticamente todos os estados do Nordeste: "[...] Ceará, Rio Grande do Norte, Paraíba, Pernambuco e parte de Alagoas estão com secas excepcionais, e todas as demais regiões enfrentam essa seca em maior ou menor grau de severidade"25.

23 BRASIL. Ministério das Cidades. Secretaria Nacional de Saneamento Ambiental - SNSA. Sistema Nacional de Informações sobre Saneamento: Diagnóstico dos Serviços de Água e Esgotos - 2015. Brasília: SNSA/MCIDADES, 2017. p. 38-42.

24 IBGE. Coordenação de Trabalho e Rendimento. Pesquisa Nacional por Amostra de Domicílios: síntese de indicadores 2014. Rio de Janeiro: IBGE, 2015. p. 66.

25 MOCUNIL, David Ferran. Depois de 5 anos consecutivos de seca, Nordeste está à beira do colapso. Rede Brasil Atual, São Paulo, 12 nov. 2016. Disponível em: 
ARMADA, Charles Alexandre Souza; LIMA, Raphael Leal Roldão. A cobrança pelo uso da água como importante instrumento jurídico-econômico da gestão hídrica no contexto da região nordeste. Revista Eletrônica Direito e Política, Programa de Pós-Graduação Stricto Sensu em Ciência Jurídica da UNIVALI, Itajaí, v.12, n.3, 30 quadrimestre de 2017. Disponível em: www.univali.br/direitoepolitica - ISSN 1980-7791

Por sua vez, segundo alerta o Centro Nacional de Monitoramento e Alertas de Desastres Naturais (Cemaden), do Ministério da Ciência, Tecnologia e Inovação em uma reportagem seriada especial sobre o tema: "o quadro atual, não só na Bahia como em todo o Nordeste, é o pior em 73 anos - o último período crítico, segundo o órgão, durou três anos, entre 1941 e 1944"26.

\subsection{BREVES CONSIDERAÇões SOBRe A POLÍticA NACIONAL DE RECURSOS HÍDRICOS}

Conforme Fernanda Barbosa Siqueira, desde 1934 o Brasil já possuía legislação sobre recursos hídricos, qual seja o Código de Água, promulgado por Getúlio Vargas, através do Decreto n. 24.643, de 10 de julho de 1934. Todavia, segundo a mesma autora, "a legislação existente não foi capaz de evitar o stress hídrico e poluição, ou mesmo conflitos sobre a sua utilização. Também não fomentou a gestão descentralizada e participativa dos recursos hídricos - um requisito absoluto hoje" 27 .

Deste modo, após mais de sessenta anos da vigência do referido Código de Águas, foi criada a Política Nacional de Recursos Hídricos - PNRH, instituída pela Lei Federal n. 9.433, de 08 de janeiro de 1997, veio regulamentar o inciso XIX do art. 21 da Constituição da República Federativa do Brasil, que previu como imprescindível - e ao mesmo tempo exigiu - a criação de um sistema nacional de gerenciamento de recursos hídricos e a definição de critérios de outorga de direitos de seu uso.

<http://www.redebrasilatual.com.br/ambiente/2016/11/depois-de-5-anos-de-seca-consecutivanordeste-esta-a-beira-do-colapso-3763.html>. Acesso em 27 jun. 2017.

${ }^{26}$ ALVES, Alan Tiago. Pior seca em 73 anos traz fome e faz população dividir água com animais.
G1-Bahia, $\quad$ Salvador,
G12 http://g1.globo.com/bahia/noticia/2017/04/pior-seca-em-73-anos-traz-fome-e-faz-populacaodividir-agua-com-animais.html>. Acesso em: 24 jun. 2017.

27 SIQUEIRA, F. B. Análise Comparativa de Instrumentos de Gestão em Áreas Protegidas e Recursos Hídricos do Brasil e da Austrália. 231p. Dissertação de Mestrado em Engenharia de Energia. Núcleo de Estudos Ambientais, Planejamento Territorial e Geomática - NEPA. Universidade Federal de Itajubá. Itajubá, MG, 2017, p. 54. Disponível em: <https://repositorio.unifei.edu.br/xmlui/handle/123456789/660>. Acesso em 25 jun. 2017. 
ARMADA, Charles Alexandre Souza; LIMA, Raphael Leal Roldão. A cobrança pelo uso da água como importante instrumento jurídico-econômico da gestão hídrica no contexto da região nordeste. Revista Eletrônica Direito e Política, Programa de Pós-Graduação Stricto Sensu em Ciência Jurídica da UNIVALI, Itajaí, v.12, n.3, 30 quadrimestre de 2017. Disponível em: www.univali.br/direitoepolitica - ISSN 1980-7791

A PNRH, ao ser instituída, de fato demonstrou buscar uma alteração da sistemática de gerenciamento hídrico vigente, assim como proporcionou uma positivação de valores e princípios acerca da imperiosa preservação e racionalização do uso da água e de seus recursos.

Deste modo, logo no art. $1^{0}$ da Lei n. 9.433/97, foram dispostos os fundamentos da PNRH, quais sejam: a) a água sendo bem de domínio público, assim como um recurso natural limitado e com valor econômico; c) o uso prioritário dos recursos hídricos para consumo humano e dessedentação de animais em situações de escassez; d) a gestão para o uso múltiplo das águas; e) a bacia hidrográfica como a unidade territorial da PNRH e demais políticas; f) a descentralização da gestão e o controle social amplo 28 .

A norma instituidora da PNRH estabeleceu os objetivos de: a) assegurar a necessária disponibilidade de água para todas as gerações; b) a utilização racional e integrada dos recursos hídricos; c) a prevenção e a defesa contra eventos hidrológicos críticos $^{29}$.

Dentre as suas inúmeras previsões, constantes de um total de cinquenta e sete artigos, a lei da PNRH também preconizou de forma expressa, no seu artigo 50, os seis instrumentos destinados a nortear e materializar a sua execução e a consequente efetivação dos seus fundamentos, objetivos e diretrizes de ação, estes dispostos nos artigos $1^{\circ}$ ao $4^{\circ}$. Nessa esteira, foram previstos os seguintes instrumentos para a PNRH: a) planos de recursos hídricos; b) enquadramento dos corpos de água em classes, segundo os usos preponderantes da água; c) outorga dos direitos de uso de recursos hídricos; d) a cobrança pelo uso de recursos hídricos; e) compensação a municípios; f) o Sistema de Informações

${ }^{28}$ BRASIL. Lei n. 9.433, de 08 de janeiro de 1997. Diário Oficial da União, 1997. Disponível em: <http://www.planalto.gov.br/ccivil_03/leis/L9433.htm>. Acesso em: 28 jun. 2017.

${ }^{29}$ BRASIL. Lei n. 9.433, de 08 de janeiro de 1997. Diário Oficial da União, 1997. Disponível em: <http://www.planalto.gov.br/ccivil_03/leis/L9433.htm>. Acesso em: 28 jun. 2017. 
ARMADA, Charles Alexandre Souza; LIMA, Raphael Leal Roldão. A cobrança pelo uso da água como importante instrumento jurídico-econômico da gestão hídrica no contexto da região nordeste. Revista Eletrônica Direito e Política, Programa de Pós-Graduação Stricto Sensu em Ciência Jurídica da UNIVALI, Itajaí, v.12, n.3, 30 quadrimestre de 2017. Disponível em: www.univali.br/direitoepolitica - ISSN 1980-7791

sobre Recursos Hídricos ${ }^{30}$.

Dentre esses instrumentos de gestão, o presente trabalho optou por analisar especificamente a cobrança pelo uso da água e a sua importância no contexto próprio da Região Nordeste, que será discutido na seção seguinte.

\section{A Cobrança pelo uso da Água e sua importância como INSTRUMENTO JURÍDICO ECONÔMICO NO CONTEXTO PRÓPRIO DA REGIÃO NORDESTE}

Segundo Rita de Cássia Munck, a cobrança pelo uso da água, na condição de um dos instrumentos da PNRH, como trazido acima, possui a finalidade de criar o equilíbrio entre a oferta e a demanda do bem, harmonizando a competição entre os usuários, promovendo a distribuição dos custos sociais, melhorando a qualidade dos efluentes lançados e criando um fundo financeiro para o setor ${ }^{31}$.

Por seu turno, a natureza jurídica da cobrança pela utilização dos recursos hídricos sempre se afigurou controversa para a doutrina pátria, havendo sustentação para considera-la como sendo "preço público", por não configurar imposto, taxa de polícia, taxa de serviço e tampouco contribuição de melhoria. Nesse sentido, pode-se mencionar as lições de Cid Tomanik Pompeu ${ }^{32}$ e Maria Luiza Machado Granziera ${ }^{33}$.

Em contrapartida, merecem menção os entendimentos críticos dos ambientalistas Celso Antônio Pacheco Fiorillo ${ }^{34}$ e Paulo Affonso Leme Machado ${ }^{35}$,

${ }^{30}$ BRASIL. Lei n. 9.433, de 08 de janeiro de 1997. Diário Oficial da União, 1997. Disponível em: <http://www.planalto.gov.br/ccivil_03/leis/L9433.htm>. Acesso em: 28 jun. 2017.

31 MUNCK, Rita de Cássia. Uso dos recursos hídricos: o caso da cobrança na bacia do Rio Paraíba do Sul. 88 f. 2006. Dissertação (Mestrado em Ciência Política), Universidade de Brasília, Brasília, 2006, p. 16

32 POMPEU, Cid Tomanick. Direito das águas no Brasil. São Paulo: Revista dos Tribunais, 2006, p. 279.

33 GRANZIERA, Maria Luiza Machado. Direito de águas: disciplina jurídica das águas doces. 2. ed. São Paulo. Atlas: 2003, p. 211. 335.

34 FIORILlO, Celso Antônio Pacheco. Curso de Direito Ambiental Brasileiro. 2009, p. 334- 
ARMADA, Charles Alexandre Souza; LIMA, Raphael Leal Roldão. A cobrança pelo uso da água como importante instrumento jurídico-econômico da gestão hídrica no contexto da região nordeste. Revista Eletrônica Direito e Política, Programa de Pós-Graduação Stricto Sensu em Ciência Jurídica da UNIVALI, Itajaí, v.12, n.3, 30 quadrimestre de 2017. Disponível em: www.univali.br/direitoepolitica - ISSN 1980-7791

os quais se opõem à classificação da água como 'bem de domínio público', conforme art. 10, da Lei n. 9.433/97. Isso porque, para os referidos autores, o Poder Público seria apenas o gestor dos recursos hídricos e não seu 'proprietário', defendendo, em suas respectivas obras, que tal categorização estaria em explícita confrontação com o texto constitucional, que considera a água um 'bem tipicamente ambiental', de uso comum do povo e, portanto, com natureza e 'propriedade' difusa.

Com efeito, para o presente trabalho, acolheu-se a posição doutrinária que considera a natureza jurídica da cobrança do uso de recursos hídricos como sendo de preço público, notadamente pelo caráter público atribuído pela $\mathrm{PNRH}$ e a finalidade proposta para esse instrumento jurídico-econômico.

Nos dizeres de Deraldo Dias de Moraes Neto, em sua tese de doutorado sobre o referido tema:

[...] em virtude da utilização da água bruta corresponder à exploração do patrimônio público, a natureza da cobrança pelo uso da água bruta só poderia ser considerada como de preço público, cabendo aos usuários arcar com os custos dessa utilização, de forma que o pagamento auferido deverá ser direcionado a custear as propostas contidas na Lei Nacional de Recursos Hídricos (Lei 9.433, de 8 de janeiro de 1997) ${ }^{36}$.

Vale ressaltar, nesse diapasão, que a cobrança decorre unicamente do uso das águas para fins econômicos, não sendo, deste modo, uma penalização ao respectivo usuário, e, por conseguinte, não possuindo relação direta com o Poder de Polícia Ambiental e a imposição de sanções pecuniárias (multas) dela decorrente.

Além disso, também cumpre explicitar que o instrumento jurídico-econômico em

35 MACHADO, Paulo Affonso Leme. Direito Ambiental Brasileiro. 21. ed. rev. ampl. atual. 2013, p. 500-501.

36 MORAES NETO, Deraldo Dias. A natureza jurídica da cobrança do uso de recursos hídricos: taxa ou preço público? 271 f. Tese (Doutorado em Direito), Universidade Federal da Bahia, Salvador, 2009, p. 205. 
ARMADA, Charles Alexandre Souza; LIMA, Raphael Leal Roldão. A cobrança pelo uso da água como importante instrumento jurídico-econômico da gestão hídrica no contexto da região nordeste. Revista Eletrônica Direito e Política, Programa de Pós-Graduação Stricto Sensu em Ciência Jurídica da UNIVALI, Itajaí, v.12, n.3, 30 quadrimestre de 2017. Disponível em: www.univali.br/direitoepolitica - ISSN 1980-7791

estudo se submete à existência de uma outorga, uma vez que se vislumbra como possível a ocorrência de cobrança de atividades e obras clandestinas ou cujos usos não tenham sido outorgados ${ }^{37}$.

Com efeito, em situações em que a outorga não é exigível, consoante o art. 12, $\S 10$, da Lei n. 9.433/1997, sustenta-se a inexigibilidade também da própria cobrança (art. 20, da mesma lei), não se confundindo esta, porém, segundo Machado ${ }^{38}$, com as isenções de recolhimento propostas pelos Comitês de bacias Hidrográficas segundo os termos do art. 38, V, da mencionada norma.

\subsection{SISTEMÁtICA GERAL DA COBRANÇA NA PNRH}

$\mathrm{O}$ art. 35, inciso X, da Lei n. 9.433/97 atribui ao Conselho Nacional de Recursos Hídricos - CNRH a competência para "estabelecer critérios gerais para a outorga de direitos de uso de recursos hídricos e para a cobrança por seu uso". Os respectivos Conselhos Recursos Hídricos dos Estados e do Distrito Federal, por sua vez, como órgãos integrantes do Sistema Nacional (art. 33, II), são competentes para estabelecer diretrizes e critérios de outorga e cobrança pelo uso de recursos hídricos estaduais.

$\mathrm{O}$ art. 37, inciso VI, da mesma lei, estabelece aos Comitês de Bacia Hidrográfica - CBHs, a competência de sugerir ao respectivo Conselho de Recursos Hídricos os mecanismos e valores de Cobrança a serem adotados na sua área de atuação.

As Agências de Água da bacia ou entidade delegatária de suas funções são instituídas mediante solicitação do $\mathrm{CBH}$ e autorização do $\mathrm{CNRH}$ ou Conselhos Estaduais, cabendo a elas desembolsarem os recursos arrecadados com a cobrança nas ações previstas no Plano de Recursos Hídricos da bacia e segundo as diretrizes estabelecidas no plano de aplicação, ambos aprovados pelo CBH.

Vale aduzir que a Cobrança em águas de domínio da União somente se inicia após a aprovação pelo Conselho Nacional de Recursos Hídricos - CNRH dos

\footnotetext{
37 MACHADO, Paulo Affonso Leme. Direito Ambiental Brasileiro. p. 549.

38 MACHADO, Paulo Affonso Leme. Direito Ambiental Brasileiro. p. 543.
} 
ARMADA, Charles Alexandre Souza; LIMA, Raphael Leal Roldão. A cobrança pelo uso da água como importante instrumento jurídico-econômico da gestão hídrica no contexto da região nordeste. Revista Eletrônica Direito e Política, Programa de Pós-Graduação Stricto Sensu em Ciência Jurídica da UNIVALI, Itajaí, v.12, n.3, 30 quadrimestre de 2017. Disponível em: www.univali.br/direitoepolitica - ISSN 1980-7791

mecanismos e valores propostos pelo $\mathrm{CBH}$. Da mesma maneira costuma se proceder com a cobrança pelo uso de recursos hídricos estaduais.

No que tange à aplicação dos valores cobrados, o art. 22, caput, da Lei da PNRH, dispôs que "os valores arrecadados com a cobrança pelo uso de recursos hídricos serão aplicados prioritariamente na bacia hidrográfica em que foram gerados", não havendo restrição para a alocação de recursos em locais ou situações fora da bacia hidrográfica ${ }^{39}$.

Ademais, segundo o supracitado artigo legal, os valores cobrados deverão ser utilizados em financiamento de estudos, programas, projetos e obras incluídos nos Planos de Recursos Hídricos, bem como para o pagamento de despesas de implantação e custeio administrativo dos órgãos e entidades integrantes do Sistema Nacional de Gerenciamento de Recursos Hídricos.

Contudo, é imperioso ressaltar que a aplicação dos valores arrecadados com a cobrança em questão não restou alocada no campo da discricionariedade. Nos dizeres de Paulo Affonso Leme Machado:

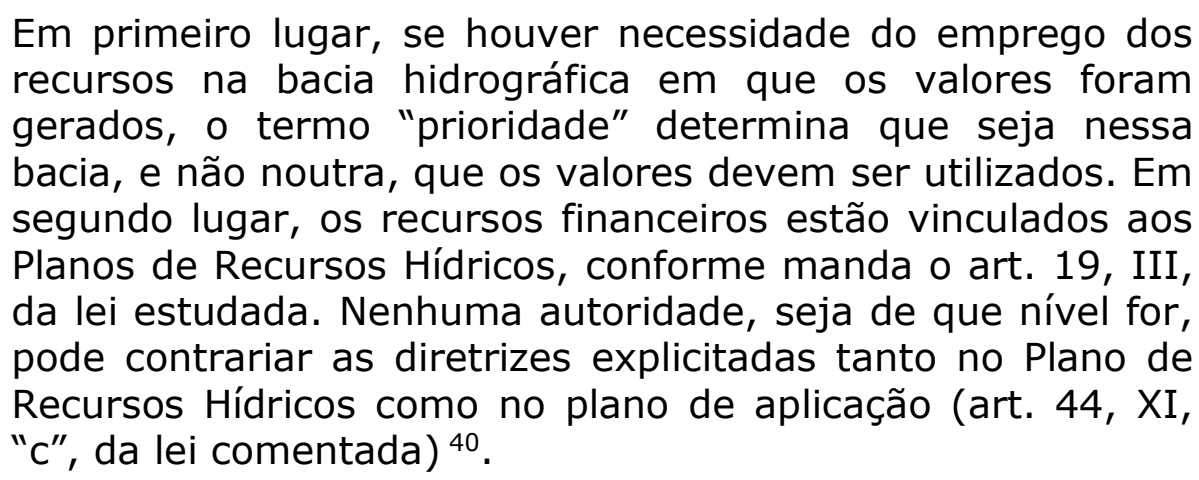

Especificamente em relação aos recursos hídricos de domínio da União, nos termos do art. 40, inciso IX, da Lei Federal n. 9.984, de 17 de julho de 2000, caberá à Agência Nacional de Águas - ANA, arrecadar, distribuir e aplicar receitas auferidas por intermédio da cobrança de uso de tais recursos hídricos.

\footnotetext{
39 BRASIL. Lei n. 9.433, de 08 de janeiro de 1997. Diário Oficial da União, 1997. Disponível em: <http://www.planalto.gov.br/ccivil_03/leis/L9433.htm>. Acesso em: 28 jun. 2017.

40 MACHADO, Paulo Affonso Leme. Direito Ambiental Brasileiro. p. 543.
} 
ARMADA, Charles Alexandre Souza; LIMA, Raphael Leal Roldão. A cobrança pelo uso da água como importante instrumento jurídico-econômico da gestão hídrica no contexto da região nordeste. Revista Eletrônica Direito e Política, Programa de Pós-Graduação Stricto Sensu em Ciência Jurídica da UNIVALI, Itajaí, v.12, n.3, 30 quadrimestre de 2017. Disponível em: www.univali.br/direitoepolitica - ISSN 1980-7791

Deste modo, a ANA operacionaliza a cobrança e recebe o dinheiro arrecadado, sendo este repassado integralmente para as agências das bacias.

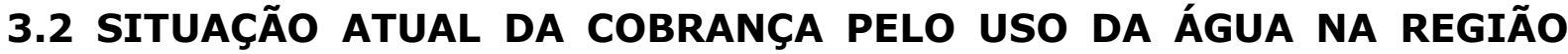 NORDESTE}

Para um país continental como o Brasil, onde coexistem diversas realidades hídricas e ambientais, é importante que a cobrança pelo uso da água seja formulada em modelos próprios, considerando as especificidades de cada região, visto que a característica regional determina uma relação diferente dos usuários para com os recursos hídricos, devendo-se levar em conta os aspectos de alocação dos recursos e as necessidades dos usuários locais.

Todavia, conforme se aquilata da doutrina, apesar de mais de uma década da edição da PNRH, não houve, ainda, a implantação do instrumento de cobrança na maioria das bacias hidrográficas do país ${ }^{41}$.

Segundo a Agência Nacional de Águas, até a presente data, em rios de domínio da União, a cobrança foi implementada somente na Bacia do Rio Paraíba do Sul, nas Bacias dos Rios Piracicaba, Capivari e Jundiaí, na Bacia do Rio Doce, na Bacia do Rio Paranaíba, na Bacia do Rio São Francisco e na Bacia do Rio Verde Grande. Dentre as referidas bacias apenas as duas últimas banham estados da região Nordeste $^{42}$.

No Estado do Ceará, desde o ano 1996, está instituída a 'tarifa' de cobrança pelo uso de recursos hídricos superficiais e subterrâneos, tendo sido o estado pioneiro no país a implementar a referida cobrança ${ }^{43}$. Entretanto, neste modelo "cobra-se

41 MORAES NETO, Deraldo Dias. A natureza jurídica da cobrança do uso de recursos hídricos: taxa ou preço público? 271 f. Tese (Doutorado em Direito), Universidade Federal da Bahia, Salvador, 2009, p. 30.

42 BRASIL. Agência Nacional de Águas - ANA. Cobrança pelo Uso de Recursos Hídricos. Disponível em: <http://www2.ana.gov.br/Paginas/servicos/cobrancaearrecadacao/cobrancaearrecadacao.aspx>. Acesso em: 29 jun. 2017.

43 MOREIRA JÚNIOR, Paulo Aloisio Novaes. As políticas ambientais de cobrança pelo uso da água na Bacia do Rio Paraíba do Sul: uma abordagem insumo-produto. 205 f. Dissertação (Mestrado em Economia). Universidade Federal da Bahia, Salvador, 2007. p. 40. 
ARMADA, Charles Alexandre Souza; LIMA, Raphael Leal Roldão. A cobrança pelo uso da água como importante instrumento jurídico-econômico da gestão hídrica no contexto da região nordeste. Revista Eletrônica Direito e Política, Programa de Pós-Graduação Stricto Sensu em Ciência Jurídica da UNIVALI, Itajaí, v.12, n.3, 30 quadrimestre de 2017. Disponível em: www.univali.br/direitoepolitica - ISSN 1980-7791

pelo serviço de fornecimento de água através de um sistema de açudes caracterizando uma cobrança pela prestação de serviço"44. Nesse sentido também é o entendimento de Philipp Hartmann ${ }^{45}$ acerca do sistema de cobrança do Ceará.

A arrecadação no sistema cearense tem por destinação, dentre outras, o custeio das atividades de gerenciamento dos recursos hídricos, abrangendo os serviços de operação e manutenção dos dispositivos e da infraestrutura hidráulica. Impende salientar que, malgrado seja denominada como tarifa, parte da cobrança no Ceará tem características de preço público ${ }^{46}$.

Na Bahia, foi introduzida em 2006 uma espécie de cobrança para o setor de saneamento e a agricultura irrigada, que se assemelha à do Ceará e, do mesmo modo que esta, "representa mais uma tarifa para a disponibilização de água através dos reservatórios da Secretaria de Recursos Hídricos da Bahia"47. Todavia, já há previsão legal de uma cobrança pelo uso da água na Bahia (conforme os objetivos e finalidades previstos na PNRH), atinente ao recurso água bruta, não tendo sido ainda implantada no Estado.

Em 2015, outro estado nordestino que já implantou a cobrança (nos moldes preconizados pela $\mathrm{PNRH}$ ) nos rios do seu domínio foi o Estado da Paraíba, que

44 VERA, Leonardo Henrique Andrade. Atuação da cobrança pelo uso da água de domínio da união como instrumento de gestão de recursos hídricos na Bacia Hidrográfica do Rio São Francisco. 166 f. Dissertação (Mestrado em Engenharia Civil). Universidade Federal de Pernambuco, Recife, 2014, p. 73.

45 HARTMANN, Philipp. A cobrança pelo uso da água como instrumento econômico na política ambiental: estudo comparativo e avaliação econômica dos modelos de cobrança pelo uso da água bruta propostos e implementados no Brasil. Porto Alegre: AEBA, 2010. p. 210.

46 BRASIL. Agência Nacional de Águas - ANA. Cobrança pelo Uso de Recursos Hídricos. Disponível

em:

<http://www2.ana.gov.br/Paginas/servicos/cobrancaearrecadacao/cobrancaearrecadacao.aspx>. Acesso em: 29 jun. 2017.

47 HARTMANN, Philipp. A cobrança pelo uso da água como instrumento econômico na política ambiental: estudo comparativo e avaliação econômica dos modelos de cobrança pelo uso da água bruta propostos e implementados no Brasil. p. 446. 
ARMADA, Charles Alexandre Souza; LIMA, Raphael Leal Roldão. A cobrança pelo uso da água como importante instrumento jurídico-econômico da gestão hídrica no contexto da região nordeste. Revista Eletrônica Direito e Política, Programa de Pós-Graduação Stricto Sensu em Ciência Jurídica da UNIVALI, Itajaí, v.12, n.3, 30 quadrimestre de 2017. Disponível em: www.univali.br/direitoepolitica - ISSN 1980-7791

iniciou, a arrecadação nas bacias do Litoral Norte, Paraíba e Litoral Sul ${ }^{48}$.

Quando se buscam os valores arrecadados no âmbito das bacias hidrográficas nordestinas, é possível mensurar ainda mais a inconteste importância do instrumento jurídico-econômico da cobrança pelo uso da água, mormente se recordado de que a aplicação desses valores - como visto acima - devem priorizar a recuperação e preservação da própria Bacia.

Nessa esteira, segundo dados da ANA, apenas no ano de 2016 a cobrança pelo uso de recursos hídricos na Bacia do Rio São Francisco arrecadou $\mathrm{R} \$$ 20.953.009,00 (vinte milhões, novecentos e cinquenta e três mil e nove reais). Desde o ano de 2010, quando a cobrança foi iniciada, já foram arrecadados $\mathrm{R} \$$ 137.972.979,00 (cento e trinta e sete milhões, novecentos e setenta e dois mil e novecentos e setenta e nove reais) ${ }^{49}$.

Por seu turno, a cobrança no Ceará, desde o início de sua implantação (novembro/1996), já arrecadou R\$ 670.023.075,00 (seiscentos e setenta milhões, vinte e três mil e setenta e cinco reais $)^{50}$. Em relação ao Estado da Paraíba, desde que foi iniciada a cobrança em janeiro de 2015, já foram arrecadados $\mathrm{R} \$ 1.133 .391,00$ (um milhão, cento e trinta e três mil e trezentos e noventa e um reais) ${ }^{51}$.

48 BRASIL. Agência Nacional de Águas - ANA. Cobrança pelo Uso de Recursos Hídricos. Disponível em: <http://www2.ana.gov.br/Paginas/servicos/cobrancaearrecadacao/cobrancaearrecadacao.aspx>. Acesso em: 29 jun. 2017

49 BRASIL. Agência Nacional de Águas - ANA. Cobrança pelo Uso de Recursos Hídricos. Disponível em: <http://www2.ana.gov.br/Paginas/servicos/cobrancaearrecadacao/cobrancaearrecadacao.aspx>. Acesso em: 29 jun. 2017

50 BRASIL. Agência Nacional de Águas - ANA. Cobrança pelo Uso de Recursos Hídricos. Disponível em: <http://www2.ana.gov.br/Paginas/servicos/cobrancaearrecadacao/cobrancaearrecadacao.aspx>. Acesso em 29 jun. 2017.

51 BRASIL. Agência Nacional de Águas - ANA. Cobrança pelo Uso de Recursos Hídricos. Disponível em: <http://www2.ana.gov.br/Paginas/servicos/cobrancaearrecadacao/cobrancaearrecadacao.aspx>. Acesso em: 29 jun. 2017 
ARMADA, Charles Alexandre Souza; LIMA, Raphael Leal Roldão. A cobrança pelo uso da água como importante instrumento jurídico-econômico da gestão hídrica no contexto da região nordeste. Revista Eletrônica Direito e Política, Programa de Pós-Graduação Stricto Sensu em Ciência Jurídica da UNIVALI, Itajaí, v.12, n.3, 30 quadrimestre de 2017. Disponível em: www.univali.br/direitoepolitica - ISSN 1980-7791

Ao analisar-se a crise hídrico-ambiental, que se manifesta em nosso planeta e que tem sido sentida e vivenciada em nosso país de forma ampla, grave e severa - principalmente pelos estados da Região Nordeste - a cobrança pelo uso da água nas Bacias Hidrográficas nordestinas se afigura como um importante e necessário instrumento de gestão hídrica.

A situação de seca prolongada na Região Nordeste, pior escassez em 73 (setenta e três) anos, exige a adoção estratégica e emergencial dos Estados, através de políticas e instrumentos que efetivem a racionalização do uso e minimizem a desigualdade na distribuição e no consumo da água.

Se os demais estados nordestinos seguirem os passos dos demais entes federativos que já adotaram a cobrança pela utilização da água, não restam dúvidas de que isso poderá garantir um sistema eficiente de disponibilidade regional do recurso, além de propiciar a reparação ou minoração de distorções no próprio uso da água.

Decerto que com a cobrança em questão se possibilita a efetiva distribuição de custos sociais "pela perda de quantidade e qualidade hídricas, de forma mais equitativa, ao incentivar uma melhoria de níveis de qualidade dos efluentes lançados nos mananciais e a racionalização do uso e captação"52.

\section{CONSIDERAÇÕES FINAIS}

A demanda por recursos hídricos do planeta tem aumentado com o próprio crescimento populacional e com o desenvolvimento de novas atividades econômicas. Destarte, tal situação sugere a adoção de medidas que considerem esse aumento de demanda, bem como os atuais índices de escassez, a distribuição não homogênea e o desperdício no tratamento adequado.

Embora o território brasileiro apresente grandes reservas de água doce, conforme exposto, destaca-se uma réplica da má distribuição apresentada no

52 MOREIRA JÚNIOR, Paulo Aloisio Novaes. As políticas ambientais de cobrança pelo uso da água na Bacia do Rio Paraíba do Sul: uma abordagem insumo-produto. 205 f. Dissertação (Mestrado em Economia). Universidade Federal da Bahia, Salvador, 2007, p. 33. 
ARMADA, Charles Alexandre Souza; LIMA, Raphael Leal Roldão. A cobrança pelo uso da água como importante instrumento jurídico-econômico da gestão hídrica no contexto da região nordeste. Revista Eletrônica Direito e Política, Programa de Pós-Graduação Stricto Sensu em Ciência Jurídica da UNIVALI, Itajaí, v.12, n.3, 30 quadrimestre de 2017. Disponível em: www.univali.br/direitoepolitica - ISSN 1980-7791

cenário internacional, somada a elevadas estatísticas de desperdício desses recursos, bem como à escassez de chuvas que prejudicam o nível de reservatórios e o acesso livre da população.

A Política Nacional de Recursos Hídricos foi instituída para buscar uma alteração da sistemática de gerenciamento hídrico vigente à época, assim como proporcionar uma positivação de valores e princípios acerca da imperiosa preservação e racionalização do uso da água e de seus recursos.

A situação dos recursos hídricos do Nordeste é bastante grave e complicada, notadamente no que tange à escassez acarretada pela seca e também pela própria ausência de políticas públicas de gestão hídricas eficientes e atentas á realidade de cada região e comunidade.

A cobrança pelo uso da água se afigura como instrumento de extrema importância no cenário nacional, e principalmente no contexto da Região Nordeste: proporciona a efetivação do aspecto econômico da água; possibilita a racionalização do seu uso, a redução das desigualdades regionais e a internalização dos custos causados pelo impacto dessa utilização.

\section{REFERÊNCIAS DAS FONTES CITADAS}

ALVES, Alan Tiago. Pior seca em 73 anos traz fome e faz população dividir água com animais. G1-Bahia, Salvador, 12 abril 2017. Disponível em: <http://g1.globo.com/bahia/noticia/2017/04/pior-seca-em-73-anos-traz-fomee-faz-populacao-dividir-agua-com-animais.html>. Acesso em: 24 jun. 2017.

BOFF, Leonardo. Sustentabilidade: o que é, o que não é. 4. ed. Petrópolis, RJ: Vozes, 2015.

BRASIL. Agência Nacional de Águas - ANA. Cobrança pelo Uso de Recursos Hídricos.

<http://www2.ana.gov.br/Paginas/servicos/cobrancaearrecadacao/cobrancaearr ecadacao.aspx>. Acesso em: 29 jun. 2017.

BRASIL. Agência Nacional de Águas - ANA. Atlas Brasil: abastecimento urbano de águas: panorama nacional. Brasília: ANA: Engecorps/Cobrape, 2010. Disponível em: <http://atlas.ana.gov.br/Atlas/downloads/atlas/Resumo\%20Executivo/Atlas\%20 Brasil\%20-\%20Volume\%201\%20-\%20Panorama\%20Nacional.pdf>. Acesso em: 24 jun. 2017. 
ARMADA, Charles Alexandre Souza; LIMA, Raphael Leal Roldão. A cobrança pelo uso da água como importante instrumento jurídico-econômico da gestão hídrica no contexto da região nordeste. Revista Eletrônica Direito e Política, Programa de Pós-Graduação Stricto Sensu em Ciência Jurídica da UNIVALI, Itajaí, v.12, n.3, 30 quadrimestre de 2017. Disponível em: www.univali.br/direitoepolitica - ISSN 1980-7791

BRASIL. Lei n. 9.433, de 08 de janeiro de 1997. Diário Oficial da União, 1997. Disponível em: <http://www.planalto.gov.br/ccivil_03/leis/L9433.htm>. Acesso em: 28 jun. 2017.

BRASIL. Ministério das Cidades. Secretaria Nacional de Saneamento Ambiental SNSA. Sistema Nacional de Informações sobre Saneamento: Diagnóstico dos Serviços de Água e Esgotos - 2015. Brasília: SNSA/MCIDADES, 2017.

\section{EBC. Mundo precisará mudar padrão de consumo para garantir abastecimento de água. Disponível em: <http://www.ebc.com.br/noticias/internacional/2015/03/mundo-precisara- \\ mudar-padrao-de-consumo-para-garantir-abastecimento>. Acesso em: 17 jun. 2017.}

FIORILlO, Celso Antônio Pacheco. Curso de Direito Ambiental Brasileiro. 2009.

GRANZIERA, Maria Luiza Machado. Direito de águas: disciplina jurídica das águas doces. 2. ed. São Paulo. Atlas: 2003.

HARTMANN, Philipp. A cobrança pelo uso da água como instrumento econômico na política ambiental: estudo comparativo e avaliação econômica dos modelos de cobrança pelo uso da água bruta propostos e implementados no Brasil. Porto Alegre: AEBA, 2010.

IBGE. Coordenação de Trabalho e Rendimento. Pesquisa Nacional por Amostra de Domicílios: síntese de indicadores 2014. Rio de Janeiro: IBGE, 2015.

MACHADO, Paulo Affonso Leme. Direito Ambiental Brasileiro. 21. ed. rev. ampl. atual. 2013.

MOCUNIL, David Ferran. Depois de 5 anos consecutivos de seca, Nordeste está à beira do colapso. Rede Brasil Atual, São Paulo, 12 nov. 2016. Disponível em: $<$ http://www.redebrasilatual.com.br/ambiente/2016/11/depois-de-5-anos-deseca-consecutiva-nordeste-esta-a-beira-do-colapso-3763.html>. Acesso em 27 jun. 2017.

MORAES NETO, Deraldo Dias. A natureza jurídica da cobrança do uso de recursos hídricos: taxa ou preço público? $271 \mathrm{f}$. Tese (Doutorado em Direito), Universidade Federal da Bahia, Salvador, 2009.

MOREIRA JÚNIOR, Paulo Aloisio Novaes. As políticas ambientais de cobrança pelo uso da água na Bacia do Rio Paraíba do Sul: uma abordagem insumoproduto. 205 f. Dissertação (Mestrado em Economia). Universidade Federal da Bahia, Salvador, 2007.

MUNCK, Rita de Cássia. Uso dos recursos hídricos: o caso da cobrança na bacia do Rio Paraíba do Sul. 88 f. 2006. Dissertação (Mestrado em Ciência Política), Universidade de Brasília, Brasília, 2006. 
ARMADA, Charles Alexandre Souza; LIMA, Raphael Leal Roldão. A cobrança pelo uso da água como importante instrumento jurídico-econômico da gestão hídrica no contexto da região nordeste. Revista Eletrônica Direito e Política, Programa de Pós-Graduação Stricto Sensu em Ciência Jurídica da UNIVALI, Itajaí, v.12, n.3, 30 quadrimestre de 2017. Disponível em: www.univali.br/direitoepolitica - ISSN 1980-7791

ONU - ORGANIZAÇÃO DAS NAÇÕES UNIDAS. World Urbanization Prospects: Revision 2014. Highlights. 2014. Disponível em: <http://goo.gl/ZaXUnE>. Acesso em: 18 jun. 2017.

POMPEU, Cid Tomanick. Direito das águas no Brasil. São Paulo: Revista dos Tribunais, 2006.

REBOUÇAS, Aldo. O paradoxo brasileiro. Cadernos Le Monde Diplomatique, São Paulo: Instituto Abaporu. n. 3, 2003.

SIQUEIRA, F. B. Análise Comparativa de Instrumentos de Gestão em Áreas Protegidas e Recursos Hídricos do Brasil e da Austrália. 231p. Dissertação de Mestrado em Engenharia de Energia. Núcleo de Estudos Ambientais, Planejamento Territorial e Geomática - NEPA. Universidade Federal de Itajubá. Itajubá, MG, 2017, p. 54. Disponível em: <https://repositorio.unifei.edu.br/xmlui/handle/123456789/660>. Acesso em 25 jun. 2017.

TREVISAN, Karina. Brasil fica na $20^{a}$ posição em ranking internacional de perda de água. G1, São Paulo, 30 mar. 2015. Disponível em: <http://g1.globo.com/economia/crise-da-agua/noticia/2015/03/brasil-fica-na20-posicao-em-ranking-internacional-de-perda-de-agua.html>. Acesso em: 25 jun. 2017.

UNESCO. Relatório Mundial das Nações Unidas sobre o Desenvolvimento de Recursos Hídricos 2015 - Água para um Mundo Sustentável. Disponível em:

<http://www.unesco.org/fileadmin/MULTIMEDIA/HQ/SC/images/WWDR2015Exe cutiveSummary_POR_web.pdf>. Acesso em: 17 jun. 2017.

UNESCO. Relatório Mundial das Nações Unidas sobre Desenvolvimento dos Recursos Hídricos 2017, Resumo Executivo. Disponível em: <http://unesdoc.unesco.org/images/0024/002475/247552por.pdf>. Acesso em: 17 jun. 2017.

VERA, Leonardo Henrique Andrade. Atuação da cobrança pelo uso da água de domínio da união como instrumento de gestão de recursos hídricos na Bacia Hidrográfica do Rio São Francisco. 166 f. Dissertação (Mestrado em Engenharia Civil). Universidade Federal de Pernambuco, Recife, 2014.

Submetido em: novembro de 2017

Aprovado em: dezembro de 2017 